\title{
Food insecurity and work impairment in people with severe mental disorders in a rural district of Ethiopia: a cross-sectional survey
}

\author{
Kebede Tirfessa ${ }^{1,2} \cdot$ Crick Lund $^{3,4} \cdot$ Girmay Medhin $^{5} \cdot$ Yohannes Hailemichael ${ }^{6} \cdot$ Kassahun Habtamu $^{7}$. \\ Abebaw Fekadu ${ }^{1,8,9} \cdot$ Charlotte Hanlon ${ }^{1,4,8}$
}

Received: 16 November 2018 / Accepted: 8 April 2019 / Published online: 19 April 2019

(c) The Author(s) 2019

\begin{abstract}
Purpose In this study, we aimed to identify factors associated with severe food insecurity and work impairment in people with severe mental disorders (SMD) in a rural African setting, with a view to identifying potential areas for intervention.

Methods A community-based, cross-sectional survey was conducted in Sodo district, south central Ethiopia. Key informantidentified people with possible SMD were referred for assessment by trained primary care workers and received confirmatory psychiatric diagnoses from psychiatric nurses using a standardized clinical interview. Food insecurity was measured using a locally validated measure, the Household Food Insecurity Access Scale (HFIAS). Work impairment was assessed using the Longitudinal Interval Follow-up Evaluation-Range of Impaired Functioning Tool. Potential moderator variables were specified a priori.

Results A total of 282 people with SMD participated in the study. The proportion of participants reporting severe food insecurity was $32.5 \%(n=94)$, with $53.6 \%(n=147)$ of participants reporting severe work impairment. In the multivariable model, severe food insecurity was associated with poor social support, experience of negative discrimination, higher disability and lower household annual income, but not with symptom severity or work impairment. Work impairment was associated significantly with symptom severity and disability.

Conclusion Work impairment and food insecurity were associated with distinct explanatory factors: predominantly social factors associated with food insecurity and clinical factors associated with work productivity. Longitudinal and intervention studies are needed to evaluate the extent to which clinical interventions need to be augmented by social interventions to alleviate food insecurity in people with SMD.
\end{abstract}

Keywords Psychosis $\cdot$ Schizophrenia $\cdot$ Bipolar disorder $\cdot$ Food insecurity $\cdot$ Work $\cdot$ Stigma and discrimination

\section{Background}

In many low-income countries, food insecurity is a pressing concern and thus ensuring food security for all segments of the population is a high priority. In a recent global analysis of 149 countries, the prevalence of any food insecurity ranged from $18.3 \%$ in the East Asian region to $76.1 \%$ in sub-Saharan Africa [1]. In Ethiopia, both chronic and transitory (seasonal) food insecurity are persistent problems for a large segment of the population [2]. The risk factors for food insecurity are low income [3], household structure and size [4] and living with disability [5].

Charlotte Hanlon

charlotte.hanlon@kcl.ac.uk

Extended author information available on the last page of the article
Severe mental disorders (SMD: including schizophrenia, bipolar disorder and depression with psychotic features) are associated with functional impairment [6], low levels of engagement in the workforce [7] and poor socioeconomic status [8]. In a qualitative study of key informants, including people with SMD and their caregivers, in rural Ethiopia, work impairment was described as one of the most important consequences of the illness [9], affected by a combination of stigma and discrimination, socio-economic status, substance use and the severity of symptoms. The consequences of not working may be particularly severe in low-income country settings, where food insecurity is a widespread concern for the rural population [1]. In a facility-based, case-control study in India, people with SMD were reported to be more deprived in terms of food insecurity ( $15.1 \%$ higher) compared to their controls [10]. In our previous study, we found 
that households of people with SMD in a rural district were more likely to be severely food insecure compared to households without a person living with SMD [11].

The importance of mental health for achieving the United Nations Sustainable Development Goals has been emphasized [12], particularly in relation to goals 1 (no poverty) and 2 (no hunger) by 2030. However, the factors associated with work impairment and food insecurity in people with SMD in LMICs have not been investigated in representative populations. A conceptual model for how SMD may be linked to food insecurity is presented in Fig. 1. Alcohol use disorder is known to complicate SMD [13] and is hypothesized to have an association with both work impairment and food insecurity in this study. The stigma associated with mental illness is high in this setting [14], with key informants reporting that stigma deprives people with SMD of full social participation, interpersonal relationships, marital and family life and even from employment [9], potentially leading to food insecurity.

The programme for improving mental health care (PRIME) [15] is a multi-country implementation research programme to implement and scale-up district-level mental health care plans which integrate mental health into primary care. PRIME brings together researchers, non-governmental organisations (NGOs), Ministry of Health partners and a range of local stakeholders in Ethiopia, India, Nepal, South Africa and Uganda.

In the present study, we aimed to identify the factors associated independently with the outcomes of severe food insecurity and work impairment in the PRIME sample of people with SMD. We hypothesized that food insecurity and work impairment would be related to one another but have distinct patterns of co-variates, and that associations would be modified by the level of social support.

\section{Methods}

\section{Study design and period}

A cross-sectional, community-based study was conducted between December 2014 and July 2015.

\section{Setting}

The study was conducted in Sodo district, in the Gurage Zone of the Southern Nations, Nationalities and Peoples' region of Ethiopia. The district is situated about $100 \mathrm{~km}$ from the capital city, Addis Ababa, and 88\% of the population dwell in rural areas [16]. The official language of the district is Amharic. In common with many other rural areas in Ethiopia, the population of Sodo district engages in subsistence, non-industrialised farming. The main livelihoods are from mixed agriculture (farming of cereals, root crops or vegetables, planting trees, Enset [Ensete ventricosum or 'false banana'] which is a staple food in south and central Ethiopia and animal husbandry). No mental health service was available in the district at the time of
Fig. 1 A conceptual model for the relationship between severe mental disorder and food insecurity

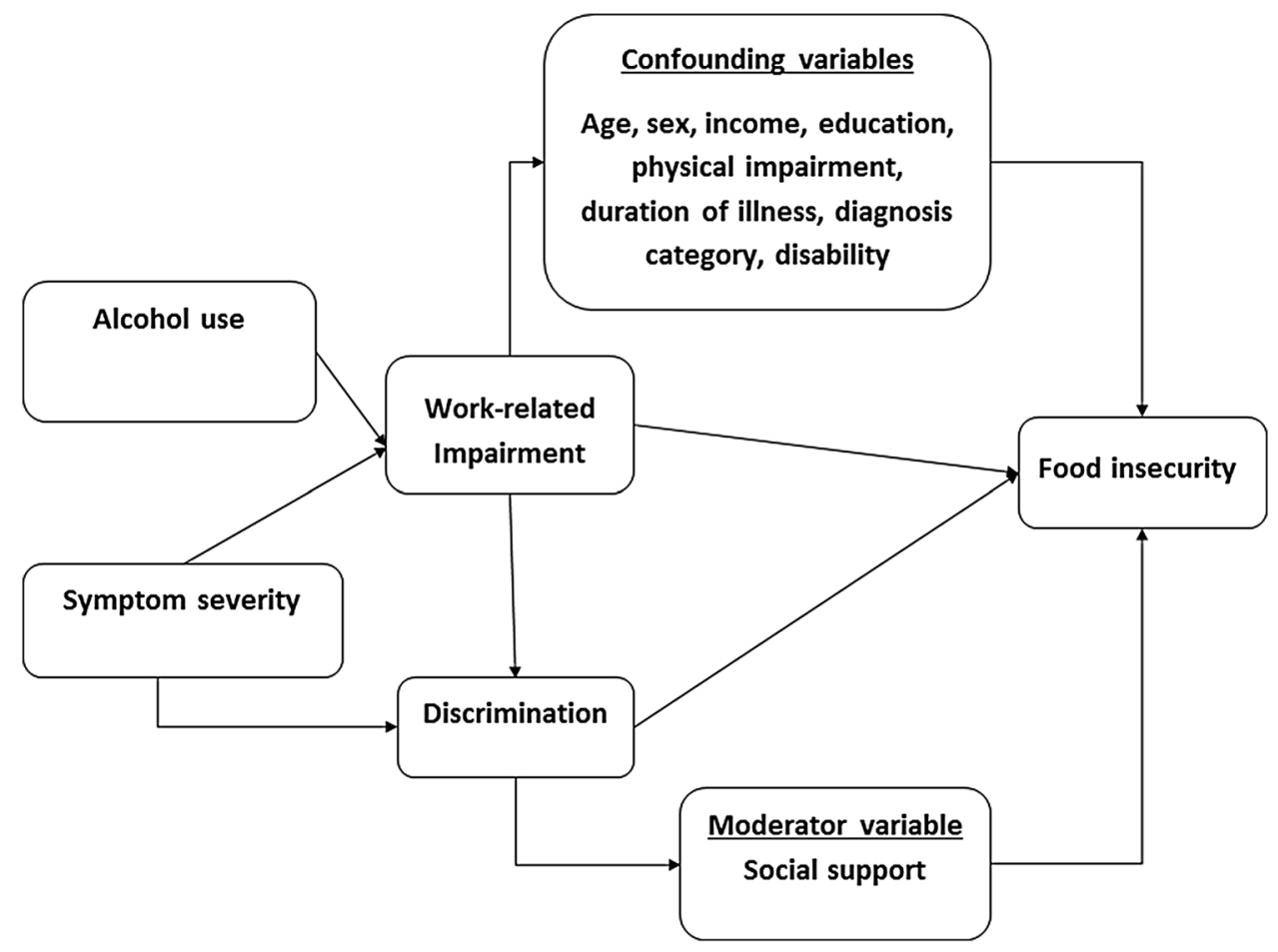


the study. The data for this study were collected at the baseline of the PRIME intervention [11]. Sodo district was selected for the PRIME study on the basis of sharing characteristics of most districts in Ethiopia [17].

\section{Participant recruitment}

Community-based health extension workers, community leaders and project outreach workers were trained for half a day on familiar presentations of SMD and epilepsy in the local context [18]. They were then asked to identify and refer and people with possible SMD or epilepsy to the closest primary health care (PHC) facility. This approach to case ascertainment was found previously to be sensitive in a neighbouring district [19]. PHC staff had been trained in the World Health Organisation mental health Gap Action Program (mhGAP) and made an initial diagnostic assessment [20]. For people who received a PHC diagnosis of psychosis or bipolar disorder, an assessment by a psychiatric nurse was carried out using the OPerational CRITeria for research (OPCRIT) to confirm the diagnosis [21]. People with epilepsy that was not co-morbid with SMD were included in a different study. Senior psychiatrists from the PRIME project provided on-site supervision, reviewed the OPCRIT forms to identify any diagnostic uncertainty and carried out diagnostic re-assessment by reviewing the charts for all cases. The specific SMD diagnoses made using the diagnostic and statistical manual for mental disorders (DSM-V) [22] criteria were categorised into "primary psychotic disorder" (schizophrenia, schizoaffective disorder, schizophreniform disorder, brief psychotic disorder, acute psychosis) and "affective psychosis" (bipolar disorder and major depressive disorder with psychotic features).

People with confirmed SMD were then invited to participate in the study if they met the following eligibility criteria:

Inclusion criteria:

- Aged 18 years or older,

- Planning to stay resident in the district for the next 12 months,

- Provided informed consent (capacity to consent was evaluated by trained psychiatric nurses with a semi-structured assessment tool used previously in a similar rural Ethiopian setting [23]) or, if lacked capacity to consent, did not refuse and guardian permission was obtained.

- Psychiatric nurse confirmed diagnosis of schizophrenia or related psychotic disorder, bipolar disorder or depression with psychotic features using the OPCRIT, and

- Able to understand Amharic, the official language of Ethiopia and the working language of the study site.
Exclusion criteria:

- If additional SMD cases were identified from the same household, they were excluded from the cohort but provided with treatment.

\section{Sample size}

The sample size for this study was based on the sample size required by the PRIME study $(N=300)$ to detect functional improvement following the PRIME intervention [24].

\section{Measures}

\section{Primary outcome: food insecurity}

The household food insecurity access scale (HFIAS) was used to assess food insecurity [25]. The HFIAS questions relate to three different access domains of food insecurity: (1) anxiety and uncertainty about food supply, (2) insufficient quality (includes variety and preferences of the type of food), and (3) insufficient food intake and its physical consequences. Households are categorized as increasingly food insecure as they respond affirmatively to more severe conditions and/or experience those conditions more frequently. The HFIAS has been translated into Amharic [26], validated in a neighbouring district and used in several research studies in Ethiopia [27]. Recommended methodology was used to obtain the HFIAS categories of: food secure, mildly food insecure, moderately food insecure and severely food insecure. For data analysis, the HFIAS categories were collapsed to give two categories: (1) food secure/mildly food insecure/ moderately food insecure and, (2) severely food insecure. This categorisation identified the most vulnerable group who would be the likely targets of future intervention and policy formulation.

\section{Secondary outcome: work-related impairment}

This was measured using the longitudinal interval follow-up evaluation-range of impaired functioning tool (LIFE-RIFT) [28]. The LIFE-RIFT is a clinician-administered tool utilizing information from the person, their caregiver and the clinician's judgment following comprehensive assessment. In this study the LIFE-RIFT was administered by psychiatric nurses. The LIFE-RIFT has been shown to be valid and reliable in high-income country settings [29] and to be acceptable, feasible and have convergent validity in the Ethiopian setting [personal communication, Fekadu, A., 2017].

The LIFE-RIFT comprises four major domains: work, interpersonal relations, satisfaction, and recreation [28]. The work domain covers employment, household and student sub-domains and assesses the degree to which a person's 
current (past week) work activities have been impaired. Our analysis focused on the work domain alone.

\section{Explanatory variables assessed by lay interviewers}

\section{Disability}

The World Health Organisation Disability Assessment Schedule (WHODAS-2.0), 36-item version, which comprises six domains, was used to assess the degree of functional impairment [30]. The WHODAS 2.0 is based on the International Classification of Functioning, Disability and Health which can be applied to any health condition and is recommended by the DSM-V Disability Study Group as the best current measure of disability for research and routine clinical practice [31]. This measure has recently been validated for use in people with SMD in the neighboring district [32], which shares many agro-ecological features with the present study setting. The six domains of WHODAS are understanding and communicating, getting around, self-care, getting along with people, life activities (household or work/school) and participation in society. During analysis, the life activities domain was excluded to avoid potential overlap with the work impairment measures existing in the LIFE-RIFT measure. The simple WHODAS scoring method was used in this study.

\section{Discrimination}

Experience of negative discrimination was measured using the discrimination and stigma scale-12 (DISC-12) [33]. The DISC-12 is an interviewer-administered scale comprising four sections. Only the section on 'unfair treatment' was included in this study. The DISC-12 has been shown to be a reliable, valid, acceptable and feasible tool in high-income country settings [33], but has not been adapted previously for Ethiopia. There are five response options for DISC-12: "not at all", "a little", "moderately", "a lot" and "not applicable". Of the 21 items in section one, two items (unfair treatment in getting welfare benefits or disability pensions and unfair treatment in the level of privacy) were excluded due to lacking face validity or comprehensibility for the study area. We conducted exploratory factor analysis using pairwise polychoric correlation due to the missing data when the item was reported to be "not applicable". All items except item 14 (unfair treatment when getting help for physical health problems) and item 15 (unfair treatment from mental health professionals) loaded onto a single dimension. Items 14 and 15 had low frequency of endorsement $(<5 \%)$ indicating that these are not salient indicators of discrimination in this setting. We, therefore, excluded items 14 and 15 and summed the remaining 17 items to give a total score indicating extent of experienced discrimination.
Socio-demographic characteristics, including age, sex and educational level, were obtained by self-report.

Alcohol use status was measured using the ten-item alcohol use disorder identification test (AUDIT) [34], which has been adapted and used in the Ethiopian setting [35].

Physical impairment was measured using the brief physical impairment checklist which was adapted by extracting items from the Washington Group General Disability Measure [36] and the Family and Wellbeing Index of physical impairment used in physical impairment and income study [37].

Annual household income and number of dependents was obtained from a household respondent and measured using items from the abbreviated version of the household survey instrument of the WHO study on global ageing and adult health which was conducted in six LMICs [38]. The measure consists of socio-economic, demographic, income and assets as its major components.

\section{Explanatory variables assessed by clinicians}

Symptom severity was assessed using the 24-item Brief Psychiatric Rating Scale-Expanded version, BPRS-E [39], which has been translated into Amharic and used in Ethiopia previously [40]. The BPRS-E is observer clinician-rated symptom scale. The clinical information on specific diagnosis and duration of illness was collected using the OPCRIT, as described above [21].

\section{Potential moderator: social support}

The level of social support was measured using the Oslo social support scale, OSS-3, which consists of three items covering the reported number of close friends and perceived concern and practical help received from others [41]. The OSS-3 was administered by trained lay interviewers. The OSS-3 has been used in previous community and facilitybased studies in an Ethiopian setting and showed good utility [42]. OSS-3 total score was generated by summing up the scores as per the recommendations of the scale developers, followed by categorisation as follows: 3-8 "poor support", 9-11 "intermediate support" and 12-14 "strong support".

\section{Training of lay interviewers}

The lay interviewers were recruited from the study area, with a minimum educational level of tenth grade. Research assistants with masters level psychology, public health and social work qualifications trained the lay interviewers for 12 days. The training covered basic interviewing skills focusing on interviewing people with SMD and their caregivers, ethical considerations when interviewing people with mental health 
problems, and in-depth training on the study measures. The training emphasized practice-oriented interview sessions.

\section{Training of clinician assessors}

Psychiatric nurses received 7 days of training from senior Ethiopian psychiatrists in the clinician-administered measures. The training included observed interviews and feedback, but formal inter-rater reliability was not undertaken.

\section{Data management and quality assurance}

Double data entry was carried out using EpiData software [43]. The first author and field supervisors provided close oversight of data collection by the lay interviewers. Psychiatrists supervised the clinical interviews. Random quality checks of questionnaires were carried out by the field supervisor and first author. The confidentiality of responses given by the respondents was ensured.

\section{Data analysis}

STATA software version 13.1 [44] was used for data analysis. The sociodemographic characteristics of study participants were summarized using descriptive statistical measures (frequencies, percentages, mean and median). Variables included in the multivariable model were those anticipated to have associations with the outcome variables on the basis of existing literature and our conceptual framework (Fig. 1). Multiple logistic regression was used to explore the factors associated with severe food insecurity and work-related impairment. Potential effect modification for the association between food insecurity and disability as well as between disability and work impairment by level of social support was explored using the Mantel-Haenszel test of homogeneity.

\section{Ethical considerations}

Ethical approval was obtained from Addis Ababa University, the College of Health Sciences, Institutional Review Board (Ref. 026/15/psy) and the Human Research Ethics Committee at the Faculty of Health Sciences, University of Cape Town (HREC REF: 412/2011). Written informed consent was obtained from the person with SMD or their caregiver, if the person with SMD lacked capacity to make the decision to participate. Non-literate participants gave finger-prints to signify their willingness to participate. Free primary carebased mental health treatment was provided via the PRIME project.

\section{Results}

Of the 1033 referred people with possible SMD or epilepsy, a total of 300 were confirmed to have SMD. See Fig. 2 for reasons for exclusion. Of the 300 people with SMD, a total of 282 eligible people with SMD were included in the study: 5 households had more than one household member with SMD and 13 cases had missing data relevant to the analyses in this paper.

\section{Sample characteristics}

Most participants were Orthodox Christians and Gurage by ethnicity (Table 1). Fewer than half of participants had attended formal education $(n=134 ; 47.5 \%)$. Most

Fig. 2 Participant flow chart

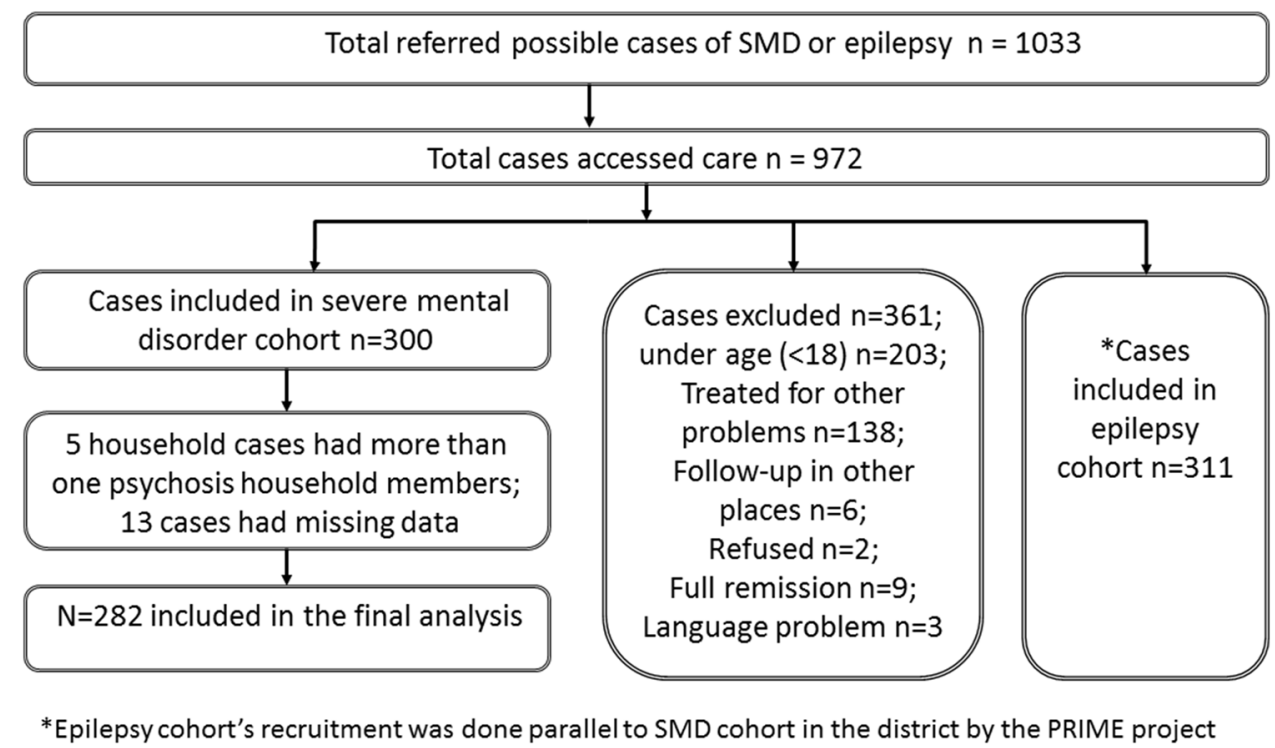


Table 1 Sociodemographic and clinical characteristics of study participants

\begin{tabular}{|c|c|c|}
\hline Characteristics & Frequency & Percent \\
\hline \multicolumn{3}{|l|}{ Educational level } \\
\hline Formal education & 134 & 47.5 \\
\hline No-formal education & 148 & 52.5 \\
\hline \multicolumn{3}{|l|}{ Sex } \\
\hline Female & 122 & 43.3 \\
\hline Male & 160 & 56.7 \\
\hline \multicolumn{3}{|l|}{ Residence } \\
\hline Urban & 59 & 21.0 \\
\hline Rural & 222 & 79.0 \\
\hline \multicolumn{3}{|l|}{ Occupation } \\
\hline Unemployed & 87 & 31.1 \\
\hline Agriculture & 70 & 25.0 \\
\hline Housewife & 57 & 20.4 \\
\hline Other & 66 & 23.5 \\
\hline \multicolumn{3}{|l|}{ Marital status } \\
\hline Single & 124 & 44.0 \\
\hline Married & 97 & 34.4 \\
\hline Divorced & 40 & 14.2 \\
\hline Other & 21 & 7.4 \\
\hline \multicolumn{3}{|l|}{ Ethnicity } \\
\hline Gurage & 268 & 95.0 \\
\hline Oromo & 10 & 3.5 \\
\hline Other & 4 & 1.5 \\
\hline \multicolumn{3}{|l|}{ Religion } \\
\hline Orthodox Christian & 254 & 90.1 \\
\hline Protestant & 18 & 6.4 \\
\hline Muslim & 9 & 3.2 \\
\hline Others & 1 & 0.4 \\
\hline \multicolumn{3}{|l|}{ Oslo social support } \\
\hline Intermediate/strong support & 195 & 69.6 \\
\hline Poor support & 85 & 30.4 \\
\hline \multicolumn{3}{|l|}{ AUDIT } \\
\hline AUDIT score $<8$ & 197 & 69.9 \\
\hline AUDIT score $\geq 8^{c}$ & 85 & 30.1 \\
\hline \multicolumn{3}{|l|}{ Diagnosis category } \\
\hline Primary psychotic disorder & 242 & 85.8 \\
\hline \multirow[t]{2}{*}{ Affective psychosis } & 40 & 14.2 \\
\hline & Mean & Standard deviation \\
\hline Age (years) & 35.6 & 13.38 \\
\hline \multirow[t]{2}{*}{ Month of assessment ${ }^{\mathrm{a}}$} & 4.3 & 3.31 \\
\hline & Median & 25 th, 75 th centiles \\
\hline Number of children & 3 & 2,5 \\
\hline Annual income $(\mathrm{ETB})^{\mathrm{b}}$ & 6000 & 3000,10750 \\
\hline DISC total & 2 & 0,7 \\
\hline
\end{tabular}

Table 1 (continued)

\begin{tabular}{lll}
\hline Characteristics & Frequency & Percent \\
\hline Physical impairment total & 1 & 0,3 \\
BPRS-E total & 48 & 35,59 \\
Duration of illness (years) & 8 & 3,20 \\
\hline
\end{tabular}

WHODAS World Health Organization Disability Assessment Schedule, LIFE-RIFT longitudinal interval follow-up evaluation-range of impaired functioning tool, DISC discrimination and stigma scale, $B P R S-E$ brief psychiatric rating scale-expanded version

${ }^{\text {a }}$ Months numbered as of January

${ }^{b}$ ETB Ethiopian Birr [USD $\approx 20.5$ Birr (for 2015)], AUDIT alcohol use disorder identification test

${ }^{\mathrm{c}}$ Includes hazardous use, harmful use and dependence

participants $(n=242 ; 85.8 \%)$ had a diagnosis of a primary psychotic disorder, with 40 (14.2\%) having an affective disorder. The median BPRS-E score (symptom severity) was 48 , [interquartile range (IQR) 35, 59]. The median duration of illness was 8 years (IQR 3, 20). During initial assessment, only $35.0 \%$ of participants reported taking antipsychotic medication.

\section{Food insecurity and work impairment}

One-third ( $n=94 ; 32.5 \%)$ of households reported severe food insecurity, with a median HFIAS score of 15 (IQR 10). More than half (53.6\%) of the participants had severe work impairment.

\section{Multivariable analyses}

1. Food insecurity

In the fully adjusted model, severe food insecurity was associated with poor social support (adjusted odds ratio (aOR) 2.87 ; 95\% CI 1.48, 5.55), negative experienced discrimination (aOR 1.08; 95\% CI 1.03, 1.14), lower annual income (aOR 4.52; 95\% CI 2.08, 9.81) and higher disability scores (aOR 1.02; 95\% CI 1.00, 1.04 ), but not with symptom severity or work impairment (Table 2). Alcohol use disorder, symptom severity and physical impairment were associated with food insecurity in the crude analyses but not in the multivariable model. There was no evidence of effect modification by social support level in the association between severe food insecurity and disability (Mantel-Haenszel test of homogeneity: $p=0.3947$ ).

2. Work-related impairment

In the fully adjusted model (Table 3), work impairment was associated independently with symptom severity (adjusted OR 1.03; 95\% CI 1.01, 1.06) and disability (adjusted OR 1.04; 95\% CI 1.03, 1.06). Having no for- 
Table 2 Factors associated with severe food insecurity in people with severe mental disorder

\begin{tabular}{|c|c|c|}
\hline Characteristics & $\begin{array}{l}\text { Crude odds ratio ( } 95 \% \\
\text { confidence interval) } \\
n=282\end{array}$ & $\begin{array}{l}\text { Adjusted odds ratio }{ }^{\mathrm{b}} \\
\text { ( } 95 \% \text { confidence interval) } \text { ) } \\
n=261\end{array}$ \\
\hline Symptom severity (BPRS-E total score) $[n=279]$ & $1.02(1.00,1.03)$ & $1.01(0.98,1.03)$ \\
\hline \multicolumn{3}{|l|}{ Oslo social support scale [ $n=277]$} \\
\hline Intermediate/strong social support & Reference & Reference \\
\hline Poor social support & $3.42(1.99,5.86)$ & $2.87(1.48,5.55)$ \\
\hline \multicolumn{3}{|l|}{ Alcohol use disorder identification test $[n=279]$} \\
\hline AUDIT $<8$ & Reference & Reference \\
\hline AUDIT $\geq 8^{\mathrm{a}}$ & $2.00(1.17,3.41)$ & $1.12(0.53,2.38)$ \\
\hline Physical impairment total $[n=279]$ & $1.37(1.15,1.64)$ & $1.17(0.93,1.47)$ \\
\hline Discrimination (DISC-12 total score) $[n=279]$ & $1.13(1.08,1.18)$ & $1.08(1.03,1.14)$ \\
\hline \multicolumn{3}{|l|}{ Work impairment $[n=271]$} \\
\hline No/mild/moderate work impairment & Reference & Reference \\
\hline Severe work impairment & $1.30(0.78,2.17)$ & $0.95(0.46,1.93)$ \\
\hline Disability (WHODAS score) ${ }^{\mathrm{c}}[n=279]$ & $1.03(1.02,1.04)$ & $1.02(1.00,1.04) \pm$ \\
\hline Age (years) & $1.00(0.98,1.02)$ & $1.01(0.98,1.03)$ \\
\hline Sex (male) $[n=279]$ & $0.90(0.54,1.49)$ & $1.17(0.59,2.31)$ \\
\hline \multicolumn{3}{|l|}{ Education $[n=279]$} \\
\hline Formal education & Reference & Reference \\
\hline No formal education & $1.06(0.64,1.74)$ & $0.63(0.31,1.25)$ \\
\hline \multicolumn{3}{|l|}{ Annual household income $(\text { Birr })^{\mathrm{d}}[n=269]$} \\
\hline 10,000 Birr or more/year & Reference & Reference \\
\hline 4000-9999 Birr/year & $2.05(1.04,4.05)$ & $1.74(0.79,3.78)$ \\
\hline$<4000$ Birr/year & $4.83(2.47,9.41)$ & $4.52(2.08,9.81)$ \\
\hline Duration of illness (years) $[n=279]$ & $1.00(0.98,1.02)$ & $1.00(0.97,1.03)$ \\
\hline \multicolumn{3}{|l|}{ Diagnosis category $[n=279]$} \\
\hline Affective psychosis & Reference & Reference \\
\hline Primary psychotic disorder & $1.57(0.73,3.36)$ & $1.41(0.56,3.59)$ \\
\hline
\end{tabular}

$B P R S-E$ brief psychiatric rating scale-expanded version

${ }^{a}$ Includes hazardous use, harmful use and dependence, WHODAS World Health Organization Disability Assessment Schedule

${ }^{\mathrm{b}}$ Adjusted for all factors listed in the table

${ }^{\mathrm{c}}$ Excluding work domain ${ }^{ \pm} p=0.021$

$\mathrm{d}_{1} \mathrm{USD} \approx 20.5 \mathrm{Birr}$ (for 2015); values in bold are statistically significant mal education was associated with work-related impairment in the crude, but not the adjusted, analyses. There was no evidence of effect modification by level of social support in the association between disability and work impairment level (Mantel-Haenszel test of homogeneity: $p=0.4593$ ).

\section{Discussion}

In this community-based sample of people with SMD from a rural Ethiopian district, work impairment and food insecurity were found to be associated with distinct, but overlapping, sets of explanatory factors: predominantly social factors associated with food insecurity and clinical factors associated with work productivity.

\section{Food insecurity}

In our previous study, we found that people with SMD reported more than double the level of severe food insecurity compared to the general population $(32.5 \%$ vs. $15.9 \%)$ [11]. In this current study, food insecurity in people with SMD was associated with poor social support, lower income, negative discrimination and functional impairment, but was not associated directly with clinical symptom severity. In cultures valuing the needs of a group or community over an individual, such as that encountered in the rural Ethiopian setting, it is commonly assumed that high levels of social support will be provided to people with mental health or other health problems. However, about one-third (30.4\%) of our sample reported poor social support. This level of social support was better than that 
Table 3 Factors associated with work impairment in people with severe mental disorder

\begin{tabular}{|c|c|c|}
\hline Characteristics & $\begin{array}{l}\text { Crude odds ratio }(95 \% \\
\text { confidence interval) } \\
n=282\end{array}$ & $\begin{array}{l}\text { Adjusted odds ratio }{ }^{\mathrm{b}} \\
\text { (95\% confidence interval) } \\
n=264\end{array}$ \\
\hline Symptom severity (BPRS-E total score) $[n=274]$ & $1.06(1.04,1.07)$ & $1.03(1.01,1.06)$ \\
\hline \multicolumn{3}{|l|}{ Oslo social support scale $[n=273]$} \\
\hline Poor social support & Reference & Reference \\
\hline Intermediate/strong social support & $0.87(0.52,1.46)$ & $0.73(0.38,1.38)$ \\
\hline \multicolumn{3}{|l|}{ Alcohol use disorder identification test $[n=274]$} \\
\hline AUDIT $\geq 8^{\mathrm{a}}$ & Reference & Reference \\
\hline AUDIT $<8$ & $0.84(0.50,1.41)$ & $0.61(0.30,1.23)$ \\
\hline Physical impairment total score $[n=274]$ & $1.13(0.95,1.34)$ & $0.96(0.77,1.18)$ \\
\hline Age (years) $[n=274]$ & $0.99(0.97,1.01)$ & $0.98(0.96,1.02)$ \\
\hline Sex (male) $[n=274]$ & $1.07(0.66,1.73)$ & $0.66(0.34,1.25)$ \\
\hline \multicolumn{3}{|l|}{ Education $[n=274]$} \\
\hline Formal education & Reference & Reference \\
\hline No formal education & $1.63(1.01,2.63)$ & $1.29(0.69,2.42)$ \\
\hline Discrimination (DISC-12 total score) $[n=274]$ & $1.00(0.97,1.03)$ & $0.98(0.94,1.02)$ \\
\hline Disability (WHODAS score) ${ }^{\mathrm{c}}$ & $1.05(1.03,1.06)$ & $1.04(1.03,1.06)$ \\
\hline \multicolumn{3}{|l|}{ Annual household income $(\operatorname{Birr})^{\mathrm{d}}[n=264]$} \\
\hline 10,000 Birr or more/year & Reference & Reference \\
\hline 4000-9999 Birr/year & $1.11(0.62,2.00)$ & $1.06(0.53,2.13)$ \\
\hline$<4000$ Birr/year & $0.99(0.55,1.78)$ & $0.96(0.47,1.97)$ \\
\hline Duration of illness (total years) $[n=274]$ & $0.98(0.97,1.00)$ & $1.00(0.97,1.03)$ \\
\hline \multicolumn{3}{|l|}{ Diagnosis category $[n=274]$} \\
\hline Affective psychosis & Reference & Reference \\
\hline Primary psychotic disorder & $1.26(0.64,2.48)$ & $0.84(0.37,1.89)$ \\
\hline
\end{tabular}

seen in the general population in the same district (poor support reported by 40.8\%) [42], which may reflect some mobilization of community support for people with SMD, albeit inadequate to address food security needs. In our qualitative work with people with SMD from the same sample, the restrictions experienced in accessing social networks were highlighted [45]. Social connectedness relies upon the capacity of a person to reciprocate; SMD may directly (via disability) and indirectly (via worsened poverty) undermine the possibility of reciprocation. People who lack interpersonal supports may then be less able to avail themselves of social opportunities which are often tied to economic opportunities, including obtaining competitive jobs and satisfactory housing [46], accessing livelihoods or obtaining financial support.

Higher perceived negative discrimination was also associated with food insecurity. Stigma and discrimination work directly against recovery in people with SMD, leading to and reinforcing social exclusion at both an individual, household and community level [47]. Because of public misconceptions about SMDs, members of society may withhold opportunities [48] and societal prejudice can significantly exacerbate the impact that psychiatric symptoms have on social opportunities [46]. In this way, the social exclusion associated with discrimination against a person or household with SMD may lead to loss of economic opportunities and financial support, and subsequent impoverishment and food insecurity. The Ethiopian Federal Ministry of Health has included mental health in the training programme to upgrade community health extension workers, including interventions to increase community awareness about the treatability of mental health problems and to counter stigmatizing attitudes [49]. Our previous work has shown that stigmatizing attitudes in health extension workers in relation to child developmental disorders are reduced by this intervention [50]. The impact of this programme on households of a person with SMD has yet to be evaluated.

Low household income was also associated with severe food insecurity in the multivariable model. This indicates that intervention programs for people with SMD may need to 
include income generation, livelihood and employment opportunities. This finding is in keeping with previous recommendations that people with SMD should be considered a vulnerable group and prioritized in community development efforts [8].

\section{Work impairment}

In this study, around half of the participants reported severe work impairment. This is noteworthy because, in the seminal World Health Organization (WHO)-led studies from the 1970s of people with SMD in LMICs, employment outcomes were found to be more favourable when compared to people with SMD in high-income country settings [51, 52]. In the followup WHO study, conducted in the 1980s and 1990s, the proportion of participants in LMICs diagnosed with "all psychoses" and reporting working (doing housework or paid work) was higher (79\%) for most of the last 2 years compared with that of high-income settings (51\%) [53]. The WHO studies have been critiqued for possible selection bias, not accounting for differential mortality and the measures used for work functioning [54]. In our study, use of the LIFE-RIFT measure may have enabled us to assess work impairment in a more comprehensive way, based on clinician judgement and drawing on all sources of information available (person with SMD, caregiver and clinical notes). Societal changes, including urbanization, may also be contributing to the higher levels of work impairment seen in our study [55].

Symptom severity and disability levels were associated strongly with work impairment, indicating that improved access to adequate mental health care may be able to support improved work functioning. However, in keeping with our proposed conceptual model, clinical symptom severity and work impairment may not determine household food insecurity, which may require interventions tackling discrimination, social isolation and potentially income security.

\section{Strengths and limitations}

Our study has a number of strengths: the population-based ascertainment of participants, as well as the use of trained clinician assessors, validated and standardized measures, and highly trained and experienced interviewers who were familiar with the sociocultural context.

In terms of limitations, we relied on self-report of physical impairment and did not measure physical ill-health in the study sample. Given the high burden of physical health problems in people with SMD [56], this could have led us to incorrectly attributing impact on work impairment and food insecurity to SMD. We also did not measure medication side effects which could adversely affect work capacity [57], although most participants were not taking psychotropic medication at the time of the study. It is possible that poverty, disability, discrimination and poor social support are all proxies for more severe and enduring illness which is then associated with food insecurity, but this is unlikely as we were able to adjust for symptom severity and duration of illness. Finally, due to the cross-sectional design, our study was also not able to draw any conclusions regarding temporal relationships or causality.

\section{Conclusions}

The complex relationships between social support, income, discrimination, illness-related disability, work impairment and food insecurity require further elucidation in a prospective study to identify the best targets for intervention. The findings from this study indicate that food insecurity in people with SMD is not just a consequence of illness severity. Although expanding access to care has the potential to improve clinical outcomes, reduce disability and improve the individual person's capacity to work, amelioration of household level food insecurity may need to additionally attend to social support, discrimination and access to livelihoods. This may require multi-sectoral working and engagement with community organisations and non-governmental organisations. The findings from this study are likely to be generalizable to other rural, food-insecure populations of sub-Saharan Africa.

Acknowledgements We would like to thank all contributors to this study; particularly the participants and their caregivers, members of Sodo district health office and the PRIME research staff.

Authors' contributions $\mathrm{KT}, \mathrm{CL}, \mathrm{AF}$ and $\mathrm{CH}$ designed the study. KT and $\mathrm{CH}$ analyzed the data. KT drafted the manuscript and received critical feedbacks from (CL, KH, GM, YHM, AF and CH). All co-authors (CL, $\mathrm{KH}, \mathrm{GM}, \mathrm{YHM}, \mathrm{AF}$ and $\mathrm{CH}$ ) read and approved the final version of the manuscript and agreed on its submission for publication.

Funding This PhD study is nested into the PRogramme for Improving Mental health carE (PRIME). PRIME was funded by the UK Department for International Development (DfID) [201446]. The views expressed in this article do not necessarily reflect the UK Government's official policies.

Availability of data and materials The data are being used for a $\mathrm{PhD}$ student (KT) for his thesis and are not, therefore, available at the present time to the general public. The data may be requested from the corresponding author for verification of the analyses in this paper.

\section{Compliance with ethical standards}

Conflict of interest The authors declare that they have no conflict of interest.

Ethical statement This study was approved by the Institutional Review Board of Addis Ababa University (Ref. 026/15/psy) and the Human Research Ethics Committee at the Faculty of Health Sciences, University of Cape Town (HREC REF: 412/2011). Study participants were 18 years and older, and written informed consent was sought before data collection from the person with SMD or their caregiver, if the person with SMD lacked capacity to make the decision to participate. Non-literate participants 
gave finger-prints to signify their willingness to participate. Free primary care-based mental health treatment was provided via the PRIME project.

Open Access This article is distributed under the terms of the Creative Commons Attribution 4.0 International License (http://creativeco mmons.org/licenses/by/4.0/), which permits unrestricted use, distribution, and reproduction in any medium, provided you give appropriate credit to the original author(s) and the source, provide a link to the Creative Commons license, and indicate if changes were made.

\section{References}

1. Jones A (2017) Food insecurity and mental health status: a global analysis of 149 countries. Am J Prev Med 53(2):264-273

2. Mengistu E, Regassa N, Yusufe A (2009) The levels, determinants and coping mechanisms of food insecure households in Southern Ethiopia: case study of Sidama, Wolaita and Guraghe Zones Oslo: Drylands Coordination Group Report no. 55

3. Ashiabi G, O'Neal K (2008) A framework for understanding the association between food insecurity and children's developmental outcomes. Child Dev Perspect 2:71-77

4. Hailu A, Regassa N (2007) Correlates of household food security in densely populated areas of southern Ethiopia: does the household structure matter? Stud Home Community Sci 1(2):85-91

5. Brucker D, Mitra S, Chaitoo N, Mauro J (2015) More likely to be poor whatever the measure: working-age persons with disabilities in the United States. Soc Sci Q 96(1):273-296

6. Whiteford H, Ferrari A, Degenhardt L, Feigin V, Vos T (2015) The global burden of mental, neurological and substance use disorders: an analysis from the Global Burden of Disease Study 2010. PLoS One 10(2):e0116820

7. Mojtabai R, Stuart E, Hwang I, Susukida R, Eaton W, Sampson $\mathrm{N}$ et al (2015) Long-term effects of mental disorders on employment in the National Comorbidity Survey 10-year follow-up. Soc Psychiatry Psychiatr Epidemiol 50(11):1657-1668

8. World Health Organization (2010) Mental Health and Poverty Project Mental health and development: targeting people with mental health conditions as a vulnerable group. WHO, Geneva

9. Habtamu K, Alem A, Hanlon C (2015) Conceptualizing and contextualizing functioning in people with severe mental disorders in rural Ethiopia: a qualitative study. BMC Psychiatry 15:34

10. Trani J-S, Venkataraman H, Mishra N, Groce NE, Jadhav S, Deshpande S (2016) Mental illness, poverty and stigma in India: a case-control study. BMJ Open 5:e06355

11. Tirfessa K, Lund C, Medhin G, Hailemichael Y, Fekadu A, Hanlon C (2017) Food Insecurity among people with severe mental disorder in a rural Ethiopian setting: a comparative, population-based study. Epidemiol Psychiatr Sci, pp 1-11 (Epub ahead of print)

12. Patel V, Saxena S, Lund C, Thornicroft G, Baingana F, Bolton P et al (2018) The Lancet Commission on global mental health and sustainable development. Lancet 392:1553-1598

13. Drake R, Brunette M (1998) Complications of severe mental illness related to alcohol and drug use disorders. Recent Dev Alcohol 14:285-299

14. Shibre T, Negash A, Kullgren G, Kebede D, Alem A, Fekadu A, Fekadu D, Medhin G, Jacobsson L (2001) Perception of stigma among family members of individuals with schizophrenia and major affective disorders in rural Ethiopia. Soc Psychiatry Psychiatr Epidemiol 36:299-303

15. Lund C, Tomlinson M, De-Silva M, Fekadu A, Shidhaye R, Jordans $M$ et al (2012) PRIME: a programme to reduce the treatment gap for mental disorders in five low- and middle-income countries. PLoS Med 9(12):e1001359
16. Federal Democratic Republic of Ethiopia (2008) Summary and statistical report of the 2007 population and housing census: population size by age and sex. Population Census Policy, Addis Ababa

17. Hanlon C, Luitel NP, Kathree T, Murhar V, Shrivasta S, Medhin G, Ssebunnya J, Fekadu A, Shidhaye R, Petersen I et al (2014) Challenges and opportunities for implementing integrated mental health care: a district level situation analysis from five low- and middle-income countries. PLoS One 9(2):e88437

18. Fekadu A, Hanlon C, Medhin G, Alem A, Selamu M, Welde-Giorgis $\mathrm{T}$ et al (2016) Development of a scalable mental healthcare plan for a rural district in Ethiopia. Br J Psychiatry 208:S4-S12

19. Shibre T, Kebede D, Alem A, Negash A, Kibreab S, Fekadu A et al (2002) An evaluation of two screening methods to identify cases with schizophrenia and affective disorders in a community survey in rural Ethiopia. Int J Soc Psychiatry 48(3):200-208

20. World Health Organization (2008) Mental health gap action programme (mhGAP): scaling up care for mental, neurological, and substance use disorders. WHO, Geneva

21. McGuffin P, Farmer AE, Harvey I (1991) A polydiagnostic application of operational criteria in studies of psychotic illness: development and reliability of the OPCRIT system. Arch Gen Psychiatry 48:764-770

22. American Psychiatric Association (2013) Diagnostic and statistical manual of mental disorders (DSM-V), 5th edn. American Psychiatric Publishing, Washington, DC

23. Hanlon C, Alem A, Medhin G, Shibre T, Ejigu DA, Negussie H, Dewey M, Wissow L, Prince M, Susser E et al (2016) Task sharing for the care of severe mental disorders in a low-income country (TaSCS): study protocol for a randomised, controlled, non-inferiority trial. Trials 17:76. https://doi.org/10.1186/s1306 3-13016-11191-x

24. Baron EC, Rathod SD, Hanlon C, Prince M, Fedaku A, Kigozi F, Jordans M, Luitel NP, Medhin G, Murhar V et al (2018) Impact of district mental health care plans on symptom severity and functioning of patients with priority mental health conditions: the programme for improving mental health care (PRIME) cohort protocol. BMC Psychiatry 18(1):61

25. Coates J (2004) Experience and expression of food insecurity across cultures: practical implications for valid measurement: Food and Nutrition Technical Assistance Project, Academy for Educational Development. Cooperative Agreement No. HRNA-00-98-00046-00. Sponsored by the United States Agency for International Development. http://www.fantaproject.org/downl oads/pdfs/Experience_Apr04.pdf. Cited 11 Aug 2005

26. Gebreyesus SH, Lunde T, Mariam DH, Woldehanna T, Lindtjørn B (2015) Is the adapted household food insecurity access scale (HFIAS) developed internationally to measure food insecurity valid in urban and rural households of Ethiopia? BMC Nutr 1:2. https://doi.org/10.1186/2055-0928-1181-1182

27. Jebena M, Taha M, Nakajima M, Lemieux A, Lemessa F, Hoffman R et al (2015) Household food insecurity and mental distress among pregnant women in southwestern Ethiopia: a cross-sectional study design. BMC Pregnancy Childbirth 15:250. https:// doi.org/10.1186/s12884-12015-10699-12885

28. Leon AC, Solomon DA, Mueller TI, Turvey CL, Endicott J, Keller MB (1999) The range of impaired functioning tool (LIFERIFT): a brief measure of functional impairment. Psychol Med 29(04):869-878

29. Judd L, Akiskal H, Schettler P, Endicott J, Leon A, Solomon D, Coryell W, Maser J, Keller M (2005) Psychosocial disability in the course of bipolar I and II disorder. Arch Gen Psychiatry 62(12):1322-1330

30. World Health Organisation (1985) Disability assessment schedule. WHO, Geneva 
31. Gold L (2014) DSM-5 and the assessment of functioning: the World Health Organization Disability Assessment Schedule 2.0 (WHODAS 2.0). J Am Acad Psychiatry Law 42:173-181

32. Habtamu K, Alem A, Medhin G, Fekadu A, Dewey M, Prince M, Hanlon C (2017) Validation of the World Health Organization Disability Assessment Schedule in people with severe mental disorders in rural Ethiopia. Health Qual Life Outcomes 15:64. https ://doi.org/10.1186/s12888-12015-10418-12889

33. Brohan E, Clement S, Rose D, Sartorius N, Thornicroft G (2013) Development and psychometric evaluation of the Discrimination and Stigma Scale (DISC). Psychiatry Res 208:33-40

34. WHO (2001) WHO AUDIT: the alcohol usedisorders identification test:guidelines for use in primary care, 2 nd edn. WHO, Geneva

35. Fekadu A, Hanlon C, Gebre-Eyesus E, Agedew M, Solomon H, Teferra S, Gebre-Eyesus T, Baheretibeb Y, Medhin G, Shibre T et al (2014) Burden of mental disorders and unmet needs among street homeless people in Addis Ababa, Ethiopia. BMC Med 12:138

36. Palmer M, Harley D (2012) Models and measurement in disability: an international review. Health Policy Plan 27(5):357-364

37. Mirowsky J, Hu PN (1996) physiacl impairment and the diminishing effects of income. Soc Forces 74(3):1073-1096

38. WHO (2013) WHO study on global ageing and adult health (SAGE). WHO, Geneva

39. Overall J, Gorham D (1962) The brief psychiatric rating scale. Psychol Rep 10:799-812

40. Youngmann R, Zilber N, Workneh F, Giel R (2008) Adapting the SRQ for Ethiopian populations: a culturally sensitive psychiatric screening instrument. Transcult Psychiatry 45(4):566-589

41. Brevik J, Dalgard O (1996) The health profile inventory. University of Oslo, Oslo

42. Fekadu A, Medhin G, Selamu M, Hailemariam M, Alem A, Breuer E et al (2014) Population level mental distress in rural Ethiopia. BMC Psychiatry 14:194 (1471-1244X/1414/1194)

43. Lauritsen JM, Bruus M (2003) Epidata (Version 3). A comprehensive tool for validated entry and documentation of data. The Epidata Association, Odense, Denmark

44. StataCorp LP (2016) Stata version 13.1. Texas, USA

45. Hailemariam M, Fekadu A, Selamu M, Medhin G, Prince M, Hanlon C (2016) Equitable access to integrated primary mental healthcare for people with severe mental disorders in Ethiopia: a formative study. Int J Equity Health 15:121
46. Corrigan PW, Penn D (1997) Disease and discrimination: two paradigms that describe severe mental illness. J Mental Health 6(4):355-366

47. Lapsley H, Nikora L, Black R (2002) "Kia Mauri Tau!”: Narratives of Recovery from Disabling Mental Health Problems, Report of the University of Waikato Mental Health Narratives Project Mental Health Commission, Wellington

48. Stephens CL, Belisle KC (1993) The 'consumer as provider' movement. J Mental Health Adm 20:178-182

49. Open University. Health education and training programme (HEAT). http://www.open.ac.uk/africa/heat/. Accessed $16 \mathrm{Apr}$ 2019

50. Tilahun D, Hanlon C, Fekadu A, Tekola B, Baheretibeb Y, Hoekstra R (2016) Stigma, explanatory models and unmet needs of caregivers of children with developmental disorders in a lowincome African country: a cross-sectional facility based survey. BMC Health Serv Res 16:152

51. WHO (1973) Report of the International Pilot Study of Schizophrenia. Report. WHO, Geneva

52. WHO (1979) Schizophrenia: an international follow-up study. Wiley, Chichester

53. Hopper K, Wanderling J (2000) Revisiting the developed versus developing country distinction in course and outcome in schizophrenia: results from ISoS, the WHO collaborative followup project. Schizophr Bull 26(4):835-846

54. Cohen A, Patel V, Thara R, Gureje O (2008) Questioning an axiom: better prognosis for schizophrenia in the developing world? Schizophr Bull 34(2):229-244

55. United Nations (2018) Department of Economic and Social Affairs World Urbanisation Prospects 2018. In.: https://population .un.org/wup/Country-Profiles/. Accessed 28 March 2019

56. Cuc M, Bobes J, Cetkovich-Bakmas M, Cohen D, Asai Itsuo, Detraux J, Gautam S, Möller H-J, Ndetei D, Newcomer J et al (2011) Physical illness in patients with severe mental disorders: I Prevalence, impact of medications and disparities in health care. World Psychiatry 10(1):52-77

57. Khalema NE, Shankar J (2014) Perspectives on employment integration, mental illness and disability, and workplace health. Adv Public Health. https://doi.org/10.1155/2014/258614

\section{Affiliations}

\section{Kebede Tirfessa ${ }^{1,2} \cdot$ Crick Lund $^{3,4} \cdot$ Girmay Medhin $^{5} \cdot$ Yohannes Hailemichael ${ }^{6} \cdot$ Kassahun Habtamu $^{7}$. Abebaw Fekadu ${ }^{1,8,9} \cdot$ Charlotte Hanlon ${ }^{1,4,8}$ (i)}

Kebede Tirfessa

kebede.tirfessa@yahoo.com

Crick Lund

crick.lund@uct.ac.za

Girmay Medhin

gtmedhin@yahoo.com

Yohannes Hailemichael

yohannes.h.michael@gmail.com

Kassahun Habtamu

kasshabmek@gmail.com

Abebaw Fekadu

abe.wassie@kcl.ac.uk
1 Department of Psychiatry, School of Medicine, College of Health Sciences, Addis Ababa University, Addis Ababa, Ethiopia

2 College of Education and Behavioral Studies, Kotebe Metropolitan University, Addis Ababa, Ethiopia

3 Alan J Flisher Centre for Public Mental Health, Department of Psychiatry and Mental Health, University of Cape Town, Cape Town, South Africa

4 Institute of Psychiatry, Psychology and Neuroscience, Health Service and Population Research Department, Centre for Global Mental Health, King's College London, London, UK

5 Aklilu Lemma Institute of Pathobiology, Addis Ababa University, Addis Ababa, Ethiopia 
6 School of Public Health, College of Health Sciences, Addis Ababa University, Addis Ababa, Ethiopia

7 College of Education and Behavioral Studies, School of Psychology, Addis Ababa University, Addis Ababa, Ethiopia
8 Centre for Innovative Drug Development and Therapeutic Trials for Africa (CDT-Africa), College of Health Sciences, Addis Ababa University, Addis Ababa, Ethiopia

9 Global Health and Infection Department, Brighton and Sussex Medical School, Brighton, UK 